\title{
A REPRESENTAÇÃO DO LIVRO EM BRAILLE EM CATÁLOGOS EM LINHA DE ACESSO PÚBLICO DE BIBLIOTECAS
}

\author{
Felipe José Lêdo* \\ Naira Christofoletti Silveira ${ }^{* *}$
}

RESUMO: Este artigo analisa como ocorre a representação, com foco na Representação Descritiva, do livro em braille em Catálogos em Linha de Acesso Público - OPACs de três bibliotecas brasileiras, tencionando trazer à tona reflexões e discussões que circunscrevem a representação enquanto fator imprescindível para que os usuários deficientes visuais possam acessar e compreender os registros bibliográficos de livros em braille disponíveis em uma biblioteca. Para tanto, recorreu-se às pesquisas bibliográfica, documental e empírica. $\mathrm{Na}$ vertente empírica desta pesquisa, examinou-se os OPACs e os registros bibliográficos de livro em braille disponíveis em três bibliotecas brasileiras de caráter público, relacionandoos com os documentos normativos vigentes que norteiam a Representação Descritiva. Embora o foco da pesquisa tenha sido a Representação Descritiva, teceu-se uma breve crítica acerca da Representação Temática. Explicita os resultados da pesquisa, assim como arrola algumas recomendações para a confecção de OPACs e de registros bibliográficos mais responsivos aos usuários deficientes visuais.

Palavras-chave: Catalogação. Representação Descritiva. Deficiência Visual. Livro em Braille.

\footnotetext{
* Bacharel em Biblioteconomia pela Universidade Federal do Estado do Rio de Janeiro, Brasil.

E-mail: lipeledo@hotmail.com.

** Doutora em Ciência da Informação pela Escola de Comunicações e Artes da Universidade de São Paulo, Brasil. Professora Adjunta na Escola de Biblioteconomia da Universidade Federal do Estado do Rio de Janeiro, Brasil. Docente permanente do Programa de Pós-Graduação em Biblioteconomia da Universidade Federal do Estado do Rio de Janeiro, Brasil.

E-mail: naira.silveira@unirio.br
}

\section{INTRODUÇÃO}

S eguindo os preceitos de acessibilidade, muitas pesquisas vêm sendo realizadas acerca do acesso de deficientes visuais aos prédios de bibliotecas, nas quais problemas relativos às barreiras arquitetônicas são abordados. Assim como as questões referentes ao acesso de deficientes visuais às informações transmitidas em sítios na internet também estão recebendo a atenção de muitos pesquisadores.

Mas, e em relação aos problemas relativos ao acesso e à compreensão de deficientes visuais às informações veiculadas em registros bibliográficos de Catálogos em Linha de Acesso Público-OPACs de bibliotecas? Quanto a essa temática não há muitas pesquisas.
O OPAC é um importante veículo, tanto para os usuários videntes como para os usuários não videntes, pois transmite informações sobre os itens existentes no acervo de uma biblioteca. Para o usuário deficiente visual interessam, particularmente, os registros bibliográficos de documentos em formatos acessíveis.

Sendo assim, a temática deste artigo circunscreve discussões direcionadas à compreensão e ao acesso de usuários deficientes visuais aos registros bibliográficos de livros em braille $^{1}$ veiculados pelos OPACs de bibliotecas.

\footnotetext{
I Neste artigo, a grafia empregada será "braille", pois "Em 10/7/05, a Comissão Brasileira do Braille-CBB recomendou a grafia 'braille', com ' $b$ ' minúsculo e dois ' 1 ' (éles), respeitando a forma original francesa, internacionalmente empregada. Porém, quando se referir ao educador Louis Braille e quando o sobrenome "Braille" fizer parte do nome de instituições, grafa-se 'Braille'." (SASSAKI, 2005, online).
} 
De acordo com a Fundação Dorina Nowill para Cegos, a deficiência visual pode ser definida como:

[...] a perda total ou parcial, congênita ou adquirida, da visão. O nível de acuidade visual pode variar, o que determina dois grupos de deficiência:

Cegueira - há perda total da visão ou pouquíssima capacidade de enxergar, o que leva a pessoa a necessitar do Sistema Braille como meio de leitura e escrita.

Baixa visão ou visão subnormal caracteriza-se pelo comprometimento do funcionamento visual dos olhos, mesmo após tratamento ou correção. As pessoas com baixa visão podem ler textos impressos ampliados ou com uso de recursos óticos especiais (FUNDAÇÃO DORINA NOWILL PARA CEGOS, [20I5d?], online).

$\mathrm{Ou}$ seja, apesar do que muitas pessoas pensam, os termos "deficiência visual" e "pessoa com deficiência visual" são compreendidos em sentido lato, sendo aplicados para designar tanto as pessoas cegas quanto as pessoas com baixa visão.

Consoante a Pesquisa Nacional de Saúde-PNS, realizada no ano de 2013, no Brasil, cerca de $3,6 \%$ da população foi atingida pela deficiência visual ${ }^{2}$ (INSTITUTO BRASILEIRO DE GEOGRAFIA E ESTATÍSTICA, 2015). Algumas das causas da deficiência visual em países em desenvolvimento são infecções, má alimentação, traumatismos e outras doenças como a catarata. Nos países desenvolvidos, a deficiência visual pode ser congênita ou adquirida ao longo da vida (ASSOCIAÇẪO BAIANA DE CEGOS, 2009).

$O$ deficiente visual, tal como qualquer pessoa, tem as mesmas necessidades informacionais. As pessoas videntes podem ler jornais, revistas, livros em tinta, ao passo que as pessoas deficientes visuais precisam ter acesso aos documentos em formatos acessíveis para desempenhar as mesmas tarefas de leitura e acesso à informação.

Nesse contexto, a necessidade de as bibliotecas formar e desenvolver coleções compostas por formatos acessíveis é

2 A PNS considerou deficiência visual os casos de cegueira de ambos os olhos, cegueira de um olho e visão reduzida do outro, cegueira de um olho e visão normal do outro e baixa visão de ambos os olhos (INSTITUTO BRASILEIRO DE GEOGRAFIA E ESTATÍSTICA, 20I5). extremamente urgente. A Catalogação desses formatos acessíveis é a atividade que veicula e comunica informações importantes para que os usuários deficientes visuais possam acessá-los.

Esta pesquisa tem como objetivo geral analisar como ocorre a representação do livro em braille em OPACs de três bibliotecas brasileiras de caráter público, tencionando refletir acerca de tal representação como fator imprescindível para que os usuários deficientes visuais possam acessar e compreender os registros bibliográficos de livros em braille disponíveis em uma biblioteca.

Cabe salientar que pesquisas no âmbito da Representação Temática que consideram características de grupos específicos de usuários são bastante comuns, ao passo que pesquisas desse tipo no âmbito da Representação Descritiva são escassas.

Apesar disso, pesquisas com foco na Representação Descritiva relacionando-a às características e necessidades de grupos específicos de usuários são perfeitamente possíveis, pois investiga-se muito pouco a relação desses grupos com a Representação Descritiva. Aliás, a Representação Descritiva emprega documentos normativos globais que muitas vezes podem ignorar as necessidades de grupos específicos de usuários.

Dessa forma, tem-se como justificativas a importância da temática para o contexto brasileiro, especialmente sobre o papel da biblioteca de caráter público no país, assim como as questões relativas à área de Organização e Representação da Informação, enfocando a Representação Descritiva e permeando a Representação Temática.

Quanto aos procedimentos metodológicos, adotou-se as pesquisas bibliográfica, documental e empírica. A pesquisa bibliográfica propiciou a revisão de literatura que, por sua vez, viabilizou o estabelecimento de uma relação entre os deficientes visuais e o acesso à informação, destacando a relevância de alguns dispositivos legais, das tecnologias assistivas, do sistema braille e da biblioteca de caráter público como fatores propulsores e facilitadores do acesso à informação; também viabilizou identificar e selecionar os documentos normativos de Representação Descritiva utilizados, quais sejam: o Código de Catalogação Anglo-Americano, segunda edição, revista-CCAA2R; os Requisitos 
Funcionais para Registros Bibliográficos-FRBR; a Declaração de Princípios Internacionais de Catalogação-DPIC; e o documento Bibliotecas para Cegos na Era da Informação: Diretrizes de Desenvolvimento.

A pesquisa documental junto à pesquisa bibliográfica oportunizou a análise e a interpretação do tratamento dado pelos documentos normativos referidos ao livro em braille. $\mathrm{Na}$ vertente empírica desta pesquisa, examinou-se os OPACs e os registros bibliográficos de livro em braille disponíveis em três bibliotecas brasileiras de caráter público, correlacionando-os com os documentos normativos.

\section{DEFICIENTE VISUAL E $O$ ACESSO À INFORMAÇÃO}

O acesso à informação é um direito de todos os cidadãos, inclusive daqueles com deficiência visual. Uma profusão de decretos, normas e leis foram instituídos para garantir a acessibilidade à informação por parte das pessoas com deficiência. De maneira bastante objetiva, a acessibilidade é a "possibilidade e condição de alcance para utilização do meio físico, meios de comunicação, produtos e serviços, por pessoa com deficiência" (ASSOCIAÇÃO BRASILEIRA DE NORMAS TÉCNICAS, 2008, p. 2).

Há vários recursos que facilitam o acesso à informação por parte dos deficientes visuais: são as chamadas tecnologias assistivas. "Com a tecnologia assistiva, as informações sobre o mundo são comunicadas de maneira mais eficiente ao deficiente visual através de seus outros sentidos, como, por exemplo, o tato e a audição" (ARAUJO, 2015, p. 22). A tecnologia assistiva busca ampliar o sentido prejudicado que, no caso do deficiente visual, é a visão, possibilitando a execução de atividades que antes pareciam quase impossíveis.

Além das tecnologias assistivas, o catálogo, enquanto conjunto de registros bibliográficos que representam os documentos existentes em um acervo, é também um instrumento de vital importância para que os usuários deficientes possam localizar e acessar a informação.

As tecnologias assistivas são essenciais para que os usuários com deficiência visual consigam lograr êxito ao navegar em catálogos de bibliotecas, sobretudo os catálogos em linha, nos quais também se incluem os registros bibliográficos de materiais impressos em sistema braille.

O sistema braille foi criado por Louis Braille, francês que ficou cego aos 3 anos de idade. Esse sistema é utilizado universalmente na leitura e escrita por pessoas cegas e foi desenvolvido e apresentado em 1825 ao Instituto Real dos Jovens Cegos de Paris, do qual Louis Braille era aluno. Seu sistema foi muito discutido pelos superiores do Instituto, pois não houve total aderência. Mesmo assim, entre os estudantes o sistema foi bem recebido, pois era simples, tornando rápida a leitura, a escrita e a aprendizagem da ortografia. Louis Braille criou também o aparelho de escrita, que consistia em uma régua de duas linhas com janelas correspondentes às células braille. Essa régua se encaixava nas extremidades laterais da prancha e o papel era colocado entre a prancha e a régua e pressionado, formando os pontos em relevo (TORRE, 2014). Segundo a Fundação Dorina Nowill para Cegos, o braille:

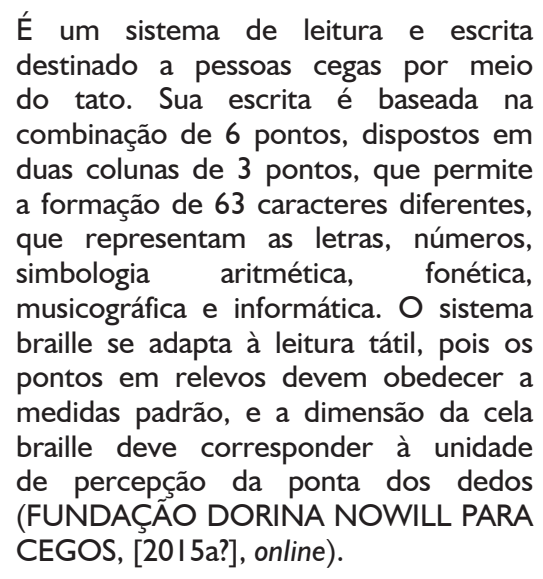

O sistema braille aportou no Brasil em 1854 por intermédio de José Álvares de Azevedo, jovem cego que também estudou no Instituto Real dos Jovens Cegos de Paris até 1850. Historicamente, o sistema braille no Brasil pode ser caracterizado tendo em vista três períodos: de 1854 a 1942, quando o sistema foi adotado e difundido no Brasil pelo Imperial Instituto dos Meninos Cegos, atual Instituto Benjamin Constant-IBC, sendo a primeira instituição latino-americana a utilizá-lo; de 1942 a 1963, quando algumas alterações foram implementadas no sistema braille em virtude da reforma ortográfica da Língua 
Portuguesa de 1942; e de 1963 a 1995, quando o Brasil esteve envolvido em várias iniciativas que objetivaram atualizar e unificar o sistema braille em nível mundial (INSTITUTO BENJAMIN CONSTANT, 2005).

No Brasil, dentre tantas entidades que atuam na disseminação do braille, a União dos Cegos do Brasil-UCB é uma das mais conhecidas. Possui como missão contribuir para a conquista da cidadania de pessoas cegas através da reabilitação, profissionalização e inserção no mercado de trabalho (UNIÃO DOS CEGOS DO BRASIL, [201-?]).

O livro em braille, enquanto um dos produtos do emprego do sistema braille, faz parte dos chamados livros acessíveis, destinados às pessoas deficientes visuais. Os livros acessíveis englobam, além do livro em braille, o livro em braille e em tinta, o livro com fonte ampliada, o livro falado ${ }^{3}$ e o livro digital Daisy ${ }^{4}$.

A Política Nacional do Livro, instituída pela Lei $\mathrm{n}^{\circ} 10.753$, de 30 out. 2003, considera que o conceito de livro contempla o livro em braille:

\begin{abstract}
Art. $\left.\right|^{\circ}$ Esta Lei institui a Política Nacional do Livro, mediante as seguintes diretrizes:

XII - assegurar às pessoas com deficiência visual o acesso à leitura.

Art. $2^{\circ}$ Considera-se livro, para efeitos desta Lei, a publicação de textos escritos em fichas ou folhas, não periódica, grampeada, colada ou costurada, em volume cartonado, encadernado ou em brochura, em capas avulsas, em qualquer formato e acabamento.

Parágrafo único. São equiparados a livro: VIII - livros impressos no Sistema Braille (BRASIL, 2003, online).
\end{abstract}

O livro em braille possui a mesma estrutura física do livro em tinta, pois sua produção requer a transcrição do livro em tinta. A única diferença reside no tamanho dos livros em braille, que são muito maiores quando comparados com os livros em tinta devido ao tamanho dos caracteres braille. Uma folha do

3 São "livros e revistas em áudio no formato MP3 [...]. O formato falado é uma ótima forma de acessibilidade para materiais de comunicação." (FUNDAÇÃO DORINA NOWILL PARA CEGOS, [2015c?], online).

4 "Disponibilizado em $C D$, permite à pessoa cega ou com visão subnormal acesso à literatura destinada ao estudo e à pesquisa de forma rápida e estruturada. [...] O livro Daisy é editado com notas de rodapé opcionais, marcadores de texto, soletração, leitura integral de abreviaturas e de sinais, além da pronúncia correta de palavras estrangeiras." (FUNDAÇÃO DORINA NOWILL PARA CEGOS, [2015b?], online). livro em tinta equivale a três folhas do livro em braille, tornando-o bastante volumoso e caro para produzir.

Quanto à Catalogação de livros em braille, essa pode ser uma tarefa complicada para muitos bibliotecários, pois nem todas as edições possuem página de rosto, obrigando o bibliotecário a catalogar utilizando a capa do livro como a fonte principal de informação. O documento Diretrizes para Serviços de Biblioteca a Usuários de Braille arrola alguns elementos que deveriam constar em cada volume do livro em braille de modo a facilitar sua Catalogação, a saber:

A página de rosto incluindo o título completo, o nome do autor, o número de volumes em braille, as quais compõem o título e as páginas de cada volume.

A declaração da data de copyright e o nome do detentor do copyright como aparece na versão impressa. A descrição do publicador do livro e a informação sobre o autor na orelha do livro [...] (FEDERAÇÃO INTERNACIONAL DE ASSOCIAÇÕES E INSTITUIÇÕES BIBLIOTECÁRIAS, 2009b, Apêndice 2, p. 97-98).

No tocante à sua guarda e preservação, o livro em braille deve ser armazenado na posição vertical nas estantes da biblioteca para evitar que os pontos em relevo não amassem tornando-se ilegíveis.

A indústria editorial braille no Brasil ainda é incipiente e monopolizada por duas instituições: a Fundação Dorina Nowill para Cegos e o IBC. No restante do mundo, a situação não é muito diferente, pois, de acordo com Torre (2014), a União Mundial de Cegos estima que, dentre os livros produzidos no mundo, apenas de $1 \%$ a $5 \%$ o são em formatos acessíveis. Isto é, mais de $90 \%$ da produção mundial é composta por livros em tinta.

Nesse contexto, o Tratado de Marraquexe, assinado em junho de 2013, busca preencher a lacuna relativa à produção das cópias em formatos acessíveis. De acordo com o tratado, países signatários, como o Brasil, devem rever suas leis de direitos autorais com a finalidade de permitir a reprodução de obras literárias e artísticas em formatos acessíveis. O deficiente visual é o principal beneficiário desse tratado, tendo em vista que o acesso à leitura e à informação poderá ser 
ampliado (ORGANIZAÇÃO MUNDIAL DA PROPRIEDADE INTELECTUAL, 2013).

Outra informação pertinente é que o Sistema Nacional de Bibliotecas Públicas-SNBP aponta a Acessibilidade como um dos critérios básicos para a composição do acervo de uma biblioteca de caráter público. Conforme esse critério, é preciso que no mínimo $5 \%$ do acervo seja formado por materiais de leitura em formato acessível (livros em braille, livros falados, livros digitais Daisy, entre outros) (SISTEMA NACIONAL DE BIBLIOTECAS PÚBLICAS, [201-?]).

Apesar de problemas relacionados à baixa produção da indústria editorial braille, defendese que a biblioteca de caráter público deve arrogar para si a responsabilidade para com os usuários do sistema braille, comprometendo-se em oferecer fácil acesso aos livros em braille.

No que concerne à existência de seções braille em bibliotecas públicas, os números são alarmantes. Em conformidade com o Censo Nacional das Bibliotecas Públicas Municipais, 91\% dessas bibliotecas não possuem serviços direcionados às pessoas com deficiência visual e apenas $9 \%$ possuem seção braille (FUNDAÇÃO GETÚLIO VARGAS, 2010).

Isso revela que poucas bibliotecas públicas municipais estão aptas a atender o deficiente visual que utiliza o braille. Presume-se que essa situação seria bastante parecida caso o censo tivesse sido realizado com bibliotecas públicas estaduais e universitárias.

A despeito da situação preocupante evidenciada anteriormente, a biblioteca de caráter público, seja ela Nacional ou Especial, Municipal ou Estadual, deve atender os usuários deficientes visuais de forma equânime, pois isso significa incluí-los social e culturalmente a partir da provisão do acesso à informação.

Para que isso aconteça, é necessário que o bibliotecário disponha de tempo para pensar estratégias e métodos para melhor atender esses usuários. A cooperação entre bibliotecas de caráter público é essencial para a otimização do tempo do bibliotecário para que ele possa desempenhar sua função social referente à inclusão das pessoas com deficiência visual. A Catalogação Cooperativa pode ser uma ótima alternativa para que tal cooperação se concretize.

Nesse contexto, o catálogo, como meio de comunicação entre a informação e o usuário, também deve abarcar uma eficiente representação de livros em braille.
Como se tornaria impossível aos usuários das bibliotecas, para escolha do mais conveniente, folhear todos os livros, ouvir todos os discos, manusear ou acessar todas as outras formas de registro disponíveis nos acervos reais ou ciberespaciais, mesmo que os materiais estivessem ampla e corretamente 'arrumados', nós, bibliotecários, elaboramos representações desses registros, de forma a simplificar a busca. Isto é, elaboramos conjuntos de informações codificadas para representar cada um dos registros do conhecimento existentes em acervos (MEY; SILVEIRA, 2009, p. 2, grifo das autoras).

Diferentemente de elaborar-se uma simples lista de referências ou um inventário, a Catalogação tem como finalidade representar os documentos, de modo a localizá-los em um acervo, separá-los segundo suas diferenças e reuni-los segundo suas semelhanças.

O processo de Catalogação resulta no registro bibliográfico, que transmite tanto as informações advindas da Representação Descritiva quanto as informações advindas da Representação Temática. É importante frisar que os catálogos em linha permitem que se faça apenas "um único registro bibliográfico, e este contém e permite vários acessos. Nos catálogos manuais, em fichas, embora o registro bibliográfico permaneça único, ele é duplicado inúmeras vezes, representando os diferentes pontos de acesso" (MEY; SILVEIRA, 2009, p. 96).

Cutter foi pioneiro ao traçar os objetivos do catálogo. Esses objetivos são aceitos até os dias de hoje.

Objetivos:

I. Permitir a uma pessoa encontrar um livro do qual ou

(A) o autor

(B) o título

(C) o assunto

2. Mostrar o que a biblioteca possui

(D) de um autor determinado

(E) de um assunto determinado

(F) de um tipo determinado de literatura

3. Ajudar na escolha de um livro

(G) de acordo com sua edição (bibliograficamente)

(H) de acordo com seu caráter (literário ou tópico) (CUTTER, 19045 , apud MEY; SILVEIRA, 2009, p. 12).

5 CUTTER, Charles Ammi. Rules for a dictionary catalog. 4th. ed. London: Library Association, 1904. 
Seguindo esses preceitos, os objetivos de um catálogo, de acordo com os Requisitos Funcionais para Registros Bibliográficos-FRBR, seriam baseados nas quatro tarefas básicas que os usuários de registros bibliográficos desempenham, a saber: encontrar, identificar, selecionar e obter.

[...] - encontrar entidades que correspondam aos critérios de busca formulados pelo usuário (isto é, localizar tanto uma única entidade quanto um conjunto de entidades num arquivo ou base de dados como resultado de uma busca que empregue um atributo ou relação da entidade);

- identificar uma entidade (isto é, confirmar que a entidade descrita corresponde à entidade procurada, ou distinguir entre duas ou mais entidades com características similares);

- selecionar uma entidade que seja apropriada às necessidades do usuário (isto é, escolher uma entidade que atenda aos requisitos do usuário no que se refere a conteúdo, formato físico, etc., ou recusar uma entidade que seja inadequada para as necessidades do usuário);

- adquirir ou obter acesso à entidade descrita (isto é, adquirir uma entidade por meio de compra, empréstimo, etc., ou ter acesso eletronicamente a uma entidade por meio de uma conexão em linha com um computador remoto) (FEDERAÇÃO INTERNACIONAL DE ASSOCIAÇÕES E INSTITUIÇÕES BIBLIOTECÁRIAS, 1998, p. 156, grifo do autor, tradução nossa).

Tais tarefas de usuários norteiam os objetivos do catálogo, publicados na Declaração de Princípios Internacionais de CatalogaçãoDPIC, a saber:

- Encontrar um conjunto de recursos que represente: todos os recursos definidos por outros critérios, tais como língua, lugar de publicação, data de publicação, tipo de suporte, etc, correspondentes a uma delimitação secundária;

- Identificar um recurso bibliográfico, isto é, confirmar que um recurso corresponde ao recurso procurado ou distinguir entre dois ou mais recursos;

- Selecionar um recurso bibliográfico adequado às suas necessidades, isto é, que esteja de acordo com suas necessidades quanto ao conteúdo, suporte, etc.

- Adquirir ou obter acesso a um recurso bibliográfico, isto é, trazer informações que permitam adquirir ou acessar um recurso através de compra, empréstimos, etc.

- Navegar em um catálogo (FEDERAÇÃO INTERNACIONAL DE ASSOCIAÇÕES E INSTITUIÇÕES BIBLIOTECÁRIAS, 2009a).

Os catálogos podem ser classificados em manuais, apresentando-se predominantemente no formato de fichas; e em automatizados, apresentando-se em linha ou em diferentes suportes, como discos compactos. Para esta pesquisa, são relevantes somente os catálogos em linha, mais especificamente os chamados OPACs.

O OPAC é um tipo de Sistema de Recuperação da Informação-SRI e pode ser compreendido, de maneira bastante simplificada, como a versão eletrônica dos catálogos manuais em fichas. As bibliotecas que implementam o OPAC devem disponibilizar uma interface com a base de dados catalográficos de modo que os usuários possam efetuar buscas nessa base.

O que torna o OPAC muito vantajoso, quando comparado com o catálogo manual, é o fato de que muitos usuários conseguem acessálo ao mesmo tempo sem precisar estar presente fisicamente na biblioteca. Para tanto, basta ter um computador conectado à internet.

\section{ANÁLISE DE OPACS E DE REGISTROS BIBLIOGRÁFICOS}

Nesta seção, serão analisadas as interfaces dos OPACs, bem como os registros bibliográficos do livro Dom Casmurro, de Machado de Assis, impresso em braille, nas seguintes bibliotecas de caráter público: Biblioteca A, Biblioteca B e Biblioteca C. Optou-se, em virtude de questões éticas, por não divulgar o nome das bibliotecas selecionadas para a consecução desta pesquisa.

Para tanto, esta seção foi subdividida em três, sendo que: em 3.1 consta a análise da Biblioteca A; em 3.2 consta a análise da Biblioteca B; em 3.3 consta a análise da Biblioteca C; e em 3.4 são apresentadas algumas considerações preliminares. 


\section{I Biblioteca A}

A pesquisa foi feita na opção "Busca combinada" através do preenchimento dos campos "Todos os campos", "Autor" e "Título". $\mathrm{O}$ operador booleano " $\mathrm{E}$ " foi utilizado visando obter uma recuperação mais precisa. O campo "Material" não contempla as opções "Braille" ou "Braile", "Livro em braille" ou "Livro em braile", o que representa dificuldade para o usuário desempenhar a tarefa de encontrar itens em braille. Em vista disso, na pesquisa realizada, o termo "Braille" foi inserido no campo "Todos os campos".

Empregando o critério de pesquisa explicitado acima, foi recuperado um único registro bibliográfico que pode ser visualizado a partir de três formatos: OPAC, MARC 21 e Dublin Core. Nesta pesquisa, serão analisados somente os formatos OPAC e MARC 21.

No formato OPAC os campos "Ent. princ." (entrada principal) e "Ent. sec." (entrada secundária) apresentam as entradas em formato de link, o que facilita percorrer, ou navegar, o catálogo. Por meio de um clique sobre esses links, recuperam-se outros livros ou documentos que possuem as mesmas entradas principal e, ou, secundária.

O campo "Assuntos" apresenta o termo "Livros para cegos" em formato de link, o que proporciona a recuperação de demais livros destinados aos usuários cegos que foram indexados sob esse mesmo termo; a existência de links facilita as tarefas de percorrer, ou navegar, o catálogo.

A despeito disso, é preciso sublinhar que o assunto "Livros para cegos" não representa adequadamente o conteúdo temático tratado pela obra, pois está relacionado estritamente ao suporte.

A indexação de obras ficcionais, como é o caso da obra em questão, pode ser efetuada levando em consideração três abordagens: a temática, propriamente dita, o gênero e o meio de expressão. A abordagem referente à temática está coberta pelas diversas listas de cabeçalhos de assuntos. A abordagem referente ao gênero abarca o tipo de obra ficcional pelo qual um autor trata de um tema, como por exemplo, o assassinato do presidente Kennedy abordado através de uma história do gênero policial. A abordagem referente ao meio de expressão identifica os meios, ou veículos, pelos quais um autor expressa sua obra: romance, filme, ópera, novelas, entre outros (BARBOSA; MEY; SILVEIRA, 2005).

O campo "Desc. física" fornece claramente a informação acerca da manifestação: "3. v. em braille ; $32 \mathrm{~cm}^{\prime \prime}$, o que demonstra tratar-se de um livro em braille; isso permite que os usuários empreendam as tarefas de identificar e selecionar os itens que correspondam às suas necessidades. O campo "Desc. física" supre a função da Designação Geral do Material-DGM, uma vez que esta não foi utilizada no formato OPAC. Ao final do registro bibliográfico, estão dispostas informações para que os usuários adquiram, ou obtenham, o livro através de empréstimo local.

No formato MARC 21 é possível observar que a DGM não foi utilizada, embora o campo 300 esteja assumindo sua função. Caso a informação sobre tratar-se de um livro em braille não tivesse sido veiculada pelo campo 300, o usuário encontraria um entrave às suas tarefas de identificar e selecionar os itens que correspondam às suas necessidades.

Foi realizada uma outra pesquisa a fim de atestar a consistência deste catálogo e verificou-se que diversos registros bibliográficos apresentaram a DGM, ao passo que outros registros não apresentaram essa informação, ou apresentaram a informação sobre o suporte no campo 300, como é o caso do registro que está sendo analisado nesta seção. Isso evidencia que há falhas quanto à padronização da Representação Descritiva de livros em braille.

Para melhor atender às tarefas de usuários deficientes visuais, esse catálogo oferece a opção de alto contraste, destinada às pessoas que possuem baixa visão, daltonismo ou pessoas que utilizam monitores monocromáticos. Basta clicar na opção "Alto contraste" para alterar o contraste da interface, eliminando as informações de cor. Para retornar à visualização normal, basta clicar novamente na opção "Alto contraste" para que a aparência original seja reestabelecida.

Para ler as informações veiculadas por esse registro bibliográfico, o usuário cego necessitará de um software leitor de tela. Alguma outra tecnologia poderia ser pensada para atender os usuários que acessam remotamente o OPAC, como por exemplo um dispositivo de leitura do registro bibliográfico acoplado aos registros bibliográficos de formatos acessíveis. 
A pessoa com baixa visão pode recorrer aos comandos para aumentar ou reduzir o tamanho da fonte da interface e dos registros bibliográficos. Essas instruções para aumento e redução de fonte constam na opção "Acessibilidade" deste OPAC.

Em conformidade com as diretrizes delineadas no documento normativo Bibliotecas para Cegos na Era da Informação: Diretrizes de Desenvolvimento, fica notório que: esse OPAC está disponível na internet para o acesso de todos; as coleções são catalogadas segundo padrões nacionais ou internacionais aceitos, vide o registro bibliográfico em MARC 21 analisado nesta seção; os registros bibliográficos, sobretudo de livros em braille, não integram catálogos coletivos nacionais e, ou, regionais; esse OPAC, devido à ausência de tecnologia adaptativa, excetuando-se a opção de alto contraste, não possibilita uma navegação independente para os usuários deficientes visuais.

\subsection{Biblioteca B}

A pesquisa foi efetuada na opção "Pesquisa Avançada" através do preenchimento dos campos "Autor", "Título" e "Biblioteca". O operador booleano " $\mathrm{e}$ " foi utilizado visando obter uma recuperação mais precisa. O campo "Tipo de Material" não contempla as opções "Braille" ou "Braile", "Livro em braille" ou "Livro em braile", o que representa dificuldade para o usuário desempenhar a tarefa de encontrar itens em braille. Como trata-se de uma biblioteca especial destinada às pessoas com deficiência visual, partiu-se do pressuposto de que seria recuperado algum livro em braille, mesmo não havendo a especificação do suporte desejado.

Empregando o critério de pesquisa explicitado acima, foi recuperado um único registro bibliográfico que pode ser visualizado a partir de três formatos: OPAC, MARC 21 e Referência Bibliográfica.

No formato OPAC os campos "Autoria Principal" e "Local/Editora" veicularam as informações no formato de link, o que facilita percorrer, ou navegar, o catálogo. Por meio de um clique sobre esses links, recuperam-se outros livros ou documentos que possuem a mesma autoria e, ou, o mesmo local e editora.
O campo "Assunto" não apresenta os assuntos tratados em formato de link, o que dificulta as tarefas de percorrer, ou navegar, o catálogo; porém, apresenta os termos "Livros para cegos" e "Romance brasileiro - Século 19".

É preciso sublinhar que o assunto "Livros para cegos" não representa adequadamente o conteúdo temático tratado pela obra, pois está relacionado estritamente ao suporte; e o assunto "Romance brasileiro - Século 19" representa somente o meio de expressão e a nacionalidade do autor.

Os campos "Descrição" e "Notas" fornecem claramente a informação acerca da manifestação: "6 pt. em braille" e "Impressão braille em 6 partes, da $24^{\text {a }}$ ed., 1991, autorizada pela Editora Ática", o que demonstra tratarse de um livro em braille; isso permite que os usuários empreendam as tarefas de identificar e selecionar os itens que correspondam às suas necessidades. Os campos "Descrição" e "Notas" suprem a função da DGM, uma vez que esta não foi utilizada no formato OPAC.

Ao final do registro bibliográfico estão dispostas informações para que os usuários cadastrados na biblioteca adquiram, ou obtenham, o item através de empréstimo local ou através dos Correios que envia o material solicitado para qualquer cidade do Brasil. Na aba "Enviar Email" é possível contatar a biblioteca.

No formato MARC 21 é possível observar a utilização da DGM, a qual favorece as tarefas dos usuários de identificar e selecionar os itens que correspondam às suas necessidades.

Caso a informação sobre tratar-se de um livro em braille não tivesse sido veiculada pelos campos 300 e 500 e pelo campo da DGM, o usuário encontraria um entrave às suas tarefas de identificar e selecionar os itens que correspondam às suas necessidades.

Foi realizada uma outra pesquisa a fim de atestar a consistência deste OPAC e verificou-se que diversos registros bibliográficos apresentaram a DGM, ao passo que outros registros não apresentaram essa informação, ou apresentaram a informação sobre o suporte no campo 300, como é o caso do registro que está sendo analisado nesta seção. Isso evidencia que há falhas quanto à padronização da Representação Descritiva de livros em braille.

Para melhor atender às tarefas de usuários deficientes visuais, esse catálogo poderia oferecer 
a opção de alto contraste, destinada às pessoas que possuem baixa visão, daltonismo ou pessoas que utilizam monitores monocromáticos. Essa ausência denota, no mínimo, uma certa incoerência, uma vez que trata-se de uma biblioteca de caráter público especial voltada para o público deficiente visual.

Para ler as informações veiculadas pelo registro bibliográfico $\mathrm{o}$ usuário deficiente visual necessitará de um software leitor de tela. Alguma outra tecnologia poderia ser pensada para atender os usuários que acessam remotamente o OPAC, como por exemplo um dispositivo de leitura do registro bibliográfico acoplado aos registros bibliográficos de formatos acessíveis.

Em conformidade com as diretrizes delineadas no documento normativo Bibliotecas para Cegos na Era da Informação: Diretrizes de Desenvolvimento, fica notório que: esse OPAC está disponível na internet para o acesso de todos; as coleções são catalogadas segundo padrões nacionais ou internacionais aceitos, vide o registro bibliográfico em MARC 21 analisado nesta seção; os registros bibliográficos, sobretudo de livros em braille, integram um catálogo coletivo regional; esse OPAC, devido à ausência de tecnologia adaptativa, não possibilita uma navegação independente para os usuários deficientes visuais.

\subsection{Biblioteca C}

A pesquisa foi feita na opção "Busca combinada" através do preenchimento dos campos "Autor", "Título" e "Material" e o operador booleano " $E$ " foi utilizado visando obter uma recuperação mais precisa. Diferentemente dos OPACs analisados anteriormente, o campo "Material" contempla a opção "Braille", permitindo ao usuário desempenhar a tarefa de encontrar itens impressos em braille.

Empregando o critério de pesquisa explicitado acima, foi recuperado um único registro bibliográfico que pode ser visualizado a partir de três formatos: OPAC, MARC 21 e Dublin Core.

No formato OPAC o campo "Ent. princ." (entrada principal) apresenta o autor em formato de link, o que facilita percorrer, ou navegar, o catálogo. Por meio de um clique sobre esse link, recuperam-se todos os livros ou documentos que possuem o mesmo autor.

O campo "Assuntos" apresenta os termos em formato de link, o que proporciona a recuperação de demais itens que estão reunidos sob esse mesmo termo; a existência de links facilita as tarefas de percorrer, ou navegar, o catálogo. Os termos empregados na indexação foram "Literatura brasileira" e "Romance": ambos inadequados, pois representam, respectivamente, somente o meio de expressão da obra e a nacionalidade do autor.

Nenhum campo fornece claramente a informação acerca da manifestação, impossibilitando que os usuários empreendam as tarefas de identificar e selecionar os itens que correspondam às suas necessidades. Isso significa um contrassenso, pois trata-se de uma biblioteca de caráter público especial e, em vista disso, deveria explicitar claramente no registro bibliográfico o tipo de suporte (manifestação), uma vez que há vários documentos neste acervo que são disponibilizados em formatos acessíveis.

Ao final do registro bibliográfico estão dispostas informações para que os usuários cadastrados na biblioteca adquiram, ou obtenham, o livro através de empréstimo local.

No formato MARC 21 é possível observar que a DGM não foi utilizada, o que pode revelar um entrave às tarefas dos usuários de identificar e selecionar os itens que correspondam às suas necessidades.

Não há informação, em quaisquer campos do MARC 21, que indique claramente tratar-se de um item em braille.

Foi realizada uma outra pesquisa a fim de atestar a consistência desse catálogo, entretanto, não foram recuperados registros bibliográficos que apresentassem a DGM.

Para melhor atender às tarefas de usuários deficientes visuais, esse catálogo oferece a opção de alto contraste, destinada às pessoas que possuem baixa visão, daltonismo ou pessoas que utilizam monitores monocromáticos. Basta clicar na opção "Alto contraste" para alterar o contraste do Terminal Web, eliminando as informações de cor. Para retornar à visualização normal, basta clicar novamente na opção "Alto contraste" para que a aparência original seja reestabelecida.

Para ler as informações veiculadas por esse registro bibliográfico, o usuário deficiente visual necessitará de um software leitor de tela. Alguma 
outra tecnologia poderia ser pensada para atender os usuários que acessam remotamente o OPAC, como um dispositivo de leitura do registro bibliográfico acoplado aos registros bibliográficos de formatos acessíveis.

A pessoa com baixa visão pode recorrer aos comandos para aumentar ou reduzir o tamanho da fonte da interface e dos registros bibliográficos. Essas instruções para aumento e redução de fonte constam na opção "Acessibilidade" deste OPAC.

Em conformidade com as diretrizes delineadas no documento normativo Bibliotecas para Cegos na Era da Informação: Diretrizes de Desenvolvimento, fica notório que: esse OPAC está disponível na internet para o acesso de todos; as coleções são catalogadas segundo padrões nacionais ou internacionais aceitos, vide o registro bibliográfico em MARC 21 analisado nessa seção; os registros bibliográficos, sobretudo de livros em braille, não integram catálogos coletivos nacionais e, ou, regionais; esse OPAC, devido à ausência de tecnologia adaptativa, excetuando-se a opção de alto contraste, não possibilita uma navegação independente para os usuários deficientes visuais.

\subsection{Considerações preliminares}

Ao analisar os OPACs e os registros bibliográficos percebeu-se que alguns deles foram estruturados de maneira mais adequada aos usuários com deficiência visual ao passo que outros não o foram.

Cabe sublinhar que, no que diz respeito à leitura das informações transmitidas pelos registros bibliográficos, o usuário deficiente visual precisará lançar mão de softwares de leitura de tela. Acredita-se que outra tecnologia poderia ser pensada para melhor atender os usuários deficientes que acessam os OPACs analisados nesta investigação, como por exemplo um dispositivo de leitura acoplado ao OPAC ou aos registros bibliográficos de documentos em formatos acessíveis.

A possibilidade de filtrar a pesquisa pelo tipo de suporte é uma característica primordial para que usuários deficientes visuais possam recuperar registros bibliográficos de livros em braille. Somente o OPAC da Biblioteca C ofereceu a opção de filtrar a pesquisa pelo suporte livro em braille, muito embora, ao analisar nesse OPAC o registro bibliográfico propriamente dito, nenhuma informação acerca do suporte tenha sido registrada.

A despeito disso, os OPACs da Biblioteca $A$ e da Biblioteca $B$ não trouxeram a opção de filtrar a pesquisa pelo suporte livro em braille, o que dificultou o encontro de registros bibliográficos de livros em braille. No caso da Biblioteca B, por tratar-se de biblioteca especial, intuiu-se que a probabilidade de encontrar livros em braille seria muito maior. Para encontrar livros em braille nesses OPACs, foi preciso preencher outros campos utilizando alguns termos, tais como: "Livro em braille" ou "Livro em braile", "Braille" ou "Braile".

Quanto aos registros bibliográficos, nas Bibliotecas A e B as informações sobre o suporte foram registradas no campo referente à descrição física do livro, o que significa que, apesar da dificuldade inicial de encontrar livros em braille, quando estes são encontrados, o usuário consegue identificá-los e selecioná-los. Nesse sentido, a utilização da DGM, apesar de ser opcional, mostra sua relevância. Somente o registro bibliográfico do OPAC da Biblioteca B apresentou a DGM no formato MARC 21. A ausência de informações acerca do suporte, tanto no campo de descrição física como no campo da DGM, como foi possível observar na Biblioteca C, significa um entrave para a identificação e a seleção de livros em braille.

No que tange à aquisição, ou obtenção do livro em braille, todos os registros bibliográficos analisados transmitiram informações necessárias para que os usuários possam adquiri-lo, ou obtêlo, por meio de empréstimo.

Os OPACs da Biblioteca A e da Biblioteca C ofereceram a opção de alto contraste, bem como as instruções para aumentar ou reduzir o tamanho da fonte da interface e dos registros bibliográficos, o que representa uma alternativa para que os usuários com baixa visão possam acessar a interface e ler os registros bibliográficos.

Ao analisar os OPACs tendo como base as diretrizes propostas pelo documento normativo Bibliotecas para Cegos na Era da Informação: Diretrizes de Desenvolvimento, nota-se que: os três catálogos estão disponíveis na internet para o acesso de todos; as coleções são catalogadas conforme padrões nacionais e internacionalmente aceitos, muito embora 
apresentem alguns problemas concernentes à inconsistência com que algumas informações são veiculadas; os registros bibliográficos de livros em formatos acessíveis não integram catálogos coletivos nacionais ou regionais, exceto aqueles da Biblioteca B, que integra um catálogo coletivo; os três OPACs não oferecem tecnologia adaptativa para que os usuários deficientes visuais possam navegar de maneira independente, excetuando-se as opções de alto contraste e as instruções para aumento e redução de fonte presentes nos OPACs da Biblioteca A e da Biblioteca C.

No que tange à Representação Temática, mais especificamente quanto à indexação, com base no vocabulário controlado proposto por Barbosa, Mey e Silveira (2005), os termos atribuídos nos três registros bibliográficos não estavam adequados. Isto posto, considerando a temática, o gênero e o meio de expressão da obra analisada, sugere-se os seguintes termos para a indexação da obra analisada: "Ciúme", "História de Família" e "Romance" (BARBOSA; MEY; SILVEIRA, 2005).

Ademais, a Biblioteca A apresentou as entradas principal, secundária e os assuntos em formato de links; a Biblioteca B apresentou, além da entrada principal, o local e a editora em formato de link; e a Biblioteca C apresentou a entrada principal e os assuntos em formato de link. Reitera-se que o link é um elemento que melhora a navegação no catálogo.

Adiante, segue o Quadro 1 que sumariza todos os quesitos analisados nesta investigação e que apresenta um resultado muito relevante para este estudo.

Quadro 1 - Resumo dos quesitos que foram analisados na pesquisa

\begin{tabular}{|c|c|c|c|c|c|}
\hline $\begin{array}{l}\text { Registros } \\
\text { bibliográficos do } \\
\text { livro em braille } \\
\text { Dom Casmurro, } \\
\text { de Machado de } \\
\text { Assis }\end{array}$ & $\begin{array}{l}\text { CCAA2R: DGM } \\
\text { e descrição física } \\
\text { (regras 1.1C e } \\
2.5 \mathrm{~B} 22 \text { ) }\end{array}$ & $\begin{array}{l}\text { FRBR e DPIC: } \\
\text { indicação do } \\
\text { atributo "forma } \\
\text { de suporte" ou } \\
\text { "tipo de suporte" } \\
\text { da manifestação } \\
\end{array}$ & $\begin{array}{l}\text { FRBR e DPIC: } \\
\text { "encontrar" }\end{array}$ & $\begin{array}{l}\text { FRBR e DPIC: } \\
\text { "identificar" e } \\
\text { "selecionar" }\end{array}$ & $\begin{array}{l}\text { FRBR e DPIC: } \\
\text { "adquirir" ou } \\
\text { "obter" }\end{array}$ \\
\hline Biblioteca A & $\begin{array}{l}\text { Não forneceu } \\
\text { a DGM, mas } \\
\text { forneceu a } \\
\text { descrição física }\end{array}$ & $\begin{array}{l}\text { O atributo foi } \\
\text { indicado somente } \\
\text { na descrição física }\end{array}$ & $\begin{array}{l}\text { Dificuldade para } \\
\text { "encontrar" livros em } \\
\text { braille, pois a pesquisa } \\
\text { por esse suporte no } \\
\text { campo "Material" } \\
\text { do OPAC não está } \\
\text { habilitada }\end{array}$ & $\begin{array}{l}\text { Foi possível } \\
\text { "identificar" e } \\
\text { "selecionar" o livro } \\
\text { em braille, pois o } \\
\text { campo descrição } \\
\text { física apresentou a } \\
\text { informação sobre a } \\
\text { manifestação }\end{array}$ & $\begin{array}{l}\text { Informações } \\
\text { sobre como } \\
\text { adquirir } \\
\text { ou obter o } \\
\text { livro em } \\
\text { braille foram } \\
\text { veiculadas no } \\
\text { registro } \\
\end{array}$ \\
\hline Biblioteca B & $\begin{array}{l}\text { Forneceu a DGM e } \\
\text { a descrição física }\end{array}$ & $\begin{array}{l}\text { O atributo foi } \\
\text { indicado na DGM, } \\
\text { na descrição física } \\
\text { e nas notas }\end{array}$ & $\begin{array}{l}\text { Dificuldade para } \\
\text { "encontrar" livros em } \\
\text { braille, pois a pesquisa } \\
\text { por esse suporte } \\
\text { no campo "Tipo de } \\
\text { Material" do OPAC } \\
\text { não está habilitada }\end{array}$ & $\begin{array}{l}\text { Foi possível } \\
\text { "identificar" e } \\
\text { "selecionar" o livro } \\
\text { em braille, pois a } \\
\text { DGM e os campos } \\
\text { descrição física e } \\
\text { notas apresentaram } \\
\text { a informação sobre a } \\
\text { manifestação }\end{array}$ & $\begin{array}{l}\text { Informações } \\
\text { sobre como } \\
\text { adquirir } \\
\text { ou obter o } \\
\text { livro em } \\
\text { braille foram } \\
\text { veiculadas no } \\
\text { registro }\end{array}$ \\
\hline Biblioteca C & $\begin{array}{l}\text { Não forneceu a } \\
\text { DGM e a descrição } \\
\text { física }\end{array}$ & $\begin{array}{l}\text { O atributo não foi } \\
\text { indicado }\end{array}$ & $\begin{array}{l}\text { Foi possível } \\
\text { "encontrar" livros em } \\
\text { braille, pois a pesquisa } \\
\text { por esse suporte no } \\
\text { campo "Material" do } \\
\text { OPAC está habilitada }\end{array}$ & $\begin{array}{l}\text { Dificuldade para } \\
\text { "identificar" e } \\
\text { "selecionar" o livro em } \\
\text { braille, pois nenhum } \\
\text { campo apresentou a } \\
\text { informação sobre a } \\
\text { manifestação }\end{array}$ & \begin{tabular}{|l} 
Informações \\
sobre como \\
adquirir \\
ou obter o \\
livro em \\
braille foram \\
veiculadas no \\
registro \\
\end{tabular} \\
\hline
\end{tabular}


(Continua)

\begin{tabular}{|l|l|l|l|l|}
\hline $\begin{array}{l}\text { Registros } \\
\text { bibliográficos do } \\
\text { livro em braille } \\
\text { Dom Casmurro, } \\
\text { de Machado de } \\
\text { Assis }\end{array}$ & $\begin{array}{l}\text { DPIC: } \\
\text { "percorrer" ou } \\
\text { "navegar" }\end{array}$ & $\begin{array}{l}\text { Bibliotecas para Cegos na Era } \\
\text { da Informação: Diretrizes de } \\
\text { Desenvolvimento }\end{array}$ & $\begin{array}{l}\text { Opção de alto contraste e } \\
\text { instruções para aumento e } \\
\text { redução de fonte }\end{array}$ & $\begin{array}{l}\text { Representação } \\
\text { Temática }\end{array}$ \\
\hline Biblioteca A & $\begin{array}{l}\text { Links para } \\
\text { entrada } \\
\text { principal, } \\
\text { secundária e } \\
\text { assuntos }\end{array}$ & $\begin{array}{l}\text { OPAC disponível na internet; } \\
\text { catalogação com base } \\
\text { em padrões nacionais ou } \\
\text { internacionais; não integra } \\
\text { catálogos coletivos; ausência de } \\
\text { tecnologia adaptativa }\end{array}$ & $\begin{array}{l}\text { Explicitou as opções de alto } \\
\text { contraste e de aumento e } \\
\text { redução de fonte }\end{array}$ & $\begin{array}{l}\text { Indexação } \\
\text { inadequada } \\
\text { termos } \\
\text { considerados } \\
\text { inadequados) }\end{array}$ \\
\hline Biblioteca B & $\begin{array}{l}\text { Links apenas } \\
\text { para autoria } \\
\text { principal, local } \\
\text { e editora; não } \\
\text { apresentou links } \\
\text { para os assuntos. }\end{array}$ & $\begin{array}{l}\text { OPAC disponível na internet; } \\
\text { catalogação com base } \\
\text { em padrões nacionais ou } \\
\text { internacionais; integra catálogo } \\
\text { coletivo; ausência de tecnologia } \\
\text { adaptativa }\end{array}$ & $\begin{array}{l}\text { Não explicitou as opções de } \\
\text { alto contraste e de aumento e } \\
\text { redução de fonte }\end{array}$ & $\begin{array}{l}\text { Indexação } \\
\text { inadequada } \\
\text { termos } \\
\text { considerados } \\
\text { inadequados) }\end{array}$ \\
\hline Biblioteca C & $\begin{array}{l}\text { Links para a } \\
\text { entrada principal } \\
\text { e para os } \\
\text { assuntos. }\end{array}$ & $\begin{array}{l}\text { OPAC disponível na internet; } \\
\text { catalogação com base } \\
\text { em padrões nacionais ou } \\
\text { internacionais; não integra } \\
\text { catálogo coletivo; ausência de } \\
\text { tecnologia adaptativa }\end{array}$ & $\begin{array}{l}\text { Explicitou as opções de alto } \\
\text { contraste e de aumento e } \\
\text { redução de fonte }\end{array}$ & $\begin{array}{l}\text { Indexação } \\
\text { inadequada } \\
\text { (termos } \\
\text { considerados } \\
\text { inadequados) }\end{array}$ \\
\hline
\end{tabular}

Fonte: Os autores (2017)

Com base no Quadro 1, ponderou-se sobre algumas circunstâncias hipotéticas de utilização dos OPACs por usuário deficiente visual, de modo a tornar mais tangíveis os resultados alcançados com este estudo. Assim sendo, o usuário deficiente visual que acessar o OPAC da Biblioteca A se deparará com os seguintes problemas: dificuldades para encontrar um livro em braille, pois não existe a opção de pesquisa pelo suporte livro em braille; dificuldades para pesquisar, de uma só vez, um determinado livro em braille e descobrir em quais bibliotecas este livro estaria disponível, tendo em vista que o OPAC não integra catálogos coletivos; dificuldades para navegar no OPAC de forma independente devido à ausência de tecnologia adaptativa; dificuldades para recuperar livros de ficção que tratem de uma temática, de um gênero e de um meio de expressão.

Caso um usuário deficiente visual acesse o OPAC da Biblioteca B, encontrará os seguintes entraves: dificuldades para encontrar um livro em braille, pois não existe a opção de pesquisa pelo suporte livro em braille; dificuldades para percorrer o catálogo e recuperar diversos documentos que estejam indexados sob um mesmo termo, já que os termos não são apresentados em formato de links; dificuldades para navegar no OPAC de forma independente devido à ausência de tecnologia adaptativa; dificuldades para ler as informações transmitidas pelo OPAC e pelos registros bibliográficos, uma vez que não está explícita as opções de alto contraste e de aumento de fonte; dificuldades para recuperar livros de ficção que tratem de uma temática, tendo em vista que a indexação levou em conta apenas o meio de expressão e a nacionalidade do autor.

Por fim, se o usuário deficiente visual optar pelo OPAC da Biblioteca C, terá que superar os seguintes obstáculos: dificuldades para identificar e selecionar livros em braille, já que a "forma de suporte" da manifestação não foi indicada em nenhum campo; dificuldades para navegar no OPAC de forma independente devido à ausência de tecnologia adaptativa; dificuldades para recuperar livros de ficção que tratem de uma temática, tendo em vista que 
a indexação levou em conta apenas o meio de expressão e a nacionalidade do autor.

Ao examinar as circunstâncias referidas, o que mais chama atenção é o fato de as bibliotecas de caráter público ditas especiais (Bibliotecas B e C) revelarem alguns problemas. As bibliotecas de caráter público especiais, teoricamente, deveriam estar mais bem preparadas para atender os usuários deficientes em todos os âmbitos, inclusive quando o assunto é estruturação de OPAC e Catalogação.

Em face dessa conjuntura, algumas recomendações foram pensadas para subsidiar a estruturação de um OPAC voltado para usuários deficientes visuais, bem como para subsidiar a Catalogação de livros em braille e de outros formatos acessíveis, a saber:

- Para que os usuários deficientes visuais possam encontrar, identificar e selecionar livros em braille e outros suportes em formatos acessíveis, deve-se criar um campo no OPAC destinado a filtrar a pesquisa de suportes em formatos acessíveis, assim como deve-se registrar as informações pertinentes ao tipo de suporte (manifestação) no momento da Catalogação, seja no campo da DGM ou no campo da descrição física;

- Deve-se registrar as informações sobre a disponibilidade do livro em braille para empréstimo para que o usuário deficiente visual possa adquiri-lo ou obtê-lo;

- Deve-se registrar as informações dos campos de entrada principal, entrada secundária e assuntos na forma de links, visando facilitar o percurso ou a navegação no OPAC;

- $\quad$ O OPAC deve estar disponível na internet;

- A Catalogação deve ser pautada em padrões nacionais ou internacionais, mas, quando necessário, algumas adaptações podem ser implementadas;

- O catálogo deve integrar uma rede de catálogos coletivos;

- Alguma tecnologia adaptativa poderia ser pensada e implementada para que os usuários deficientes visuais possam decodificar as informações veiculadas pelo registro bibliográfico;

- $\quad$ O OPAC deve trazer instruções explícitas sobre a utilização do alto contraste e do aumento e redução de fonte;
- A indexação de obras ficcionais deve considerar três abordagens: a temática, propriamente dita, o gênero e o meio de expressão.

As recomendações acima devem ser aprofundadas de acordo com cada política de Catalogação institucional, respeitando sempre as necessidades dos usuários. Por isso, acredita-se que a Catalogação não é um trabalho puramente tecnicista, como reforçada por alguns autores, ela é fruto de construção reflexiva e possui fundamentos que a direciona.

\section{CONSIDERAÇÕES FINAIS}

Esta investigação analisou a representação do livro em braille Dom Casmurro, de Machado de Assis, em OPACs de bibliotecas brasileiras de caráter público, mais especificamente da Biblioteca A, da Biblioteca B e da Biblioteca C, a fim de trazer à tona discussões e reflexões acerca de tal representação como fator essencial para que os usuários deficientes visuais possam acessar e compreender os registros bibliográficos de livros em braille.

O OPAC, foco desta investigação, foi apontado como um instrumento que trouxe novos ares à Catalogação, tornando mais célere o fornecimento de informações catalográficas aos usuários. A respeito do trabalho do catalogador, a Catalogação Cooperativa é uma atividade importante que deveria ser pensada por bibliotecários que trabalham em bibliotecas que salvaguardam documentos disponíveis em formatos acessíveis. Com a Catalogação Cooperativa, o bibliotecário poupa tempo com a Catalogação e, dessa maneira, acaba sobrando-lhe tempo para debruçar-se sobre outras questões inerentes à profissão, como, por exemplo, a oferta de um OPAC e a confecção de registros bibliográficos mais responsivos às necessidades de usuários deficientes visuais. Contudo, é relevante frisar que para que ocorra a Catalogação cooperativa é preciso que as bibliotecas que integram a rede de cooperação adotem os mesmos padrões de Catalogação.

Salienta-se que esta pesquisa não se esgota em si mesma, podendo ser aprofundada posteriormente. Um desdobramento viável seria a realização de um estudo de uso destes 
OPACs por parte de usuários deficientes visuais correlacionando-o com os registros bibliográficos de modo a verificar se estes registros respondem às necessidades de uso dos usuários. $\mathrm{E}$, com base na opinião dos usuários, propor um padrão para a Catalogação de livros em formatos acessíveis, bem como propor também uma melhor estruturação de OPACs de modo a atender os usuários deficientes visuais.

Outro desdobramento de estudo futuro seria a comparação de registros bibliográficos de livros em braille utilizando o CCAA2R e a Resource Description and Access-RDA. Esse estudo comparativo poderia fornecer indícios acerca de qual código norteia da melhor forma a Catalogação de livros em braille.

Há uma lacuna referente à realização de estudos que relacionam grupos específicos de usuários com a Representação Descritiva e este estudo buscou contribuir neste sentido. Sabe-se que a Representação Descritiva está fundamentada numa série de normas e diretrizes presentes em documentos internacionalmente utilizados, mas, muitas vezes, essas normas e diretrizes não dão conta de atender as necessidades de grupos específicos de usuários. Embora nesta pesquisa não se tenha constatado a necessidade de adaptação das normas e diretrizes vigentes, defende-se que estas devem ser sempre adaptadas quando preciso for para melhor atender grupos específicos de usuários, como é o caso dos deficientes visuais.

A Representação Descritiva não é uma atividade absolutamente técnica, pois o bibliotecário precisa refletir para catalogar, devendo sempre levar em conta o grupo de usuários para quem está catalogando. À guisa de conclusão, com este trabalho pretende-se comunicar a todos os bibliotecários catalogadores a seguinte mensagem: não basta saber catalogar, é preciso, também, saber para quem catalogar. Acredita-se que essa frase traduz perfeitamente a temática e as reflexões circunscritas nesta investigação.

Artigo recebido em I4/03/20I7 e aceito para publicação em 20/07/20I7

\section{THE REPRESENTATION OF THE BOOK IN BRAILLE IN ONLINE PUBLIC ACCESS CATALOG OF LIBRARIES}

ABSTRACT: This paper analyze how the representation takes place, with a focus on Descriptive Representation, of book in braille in Online Public Access Catalog-OPACs of Brazilian libraries, intending to bring out reflections and discussions that circumscribe the representation as a necessary factor for the visually impaired users can access and understand the bibliographic records of books in braille available in a library. We used the bibliographic research, documentary research and empirical research. In the empirical aspect of this research, we examined the OPACs and bibliographic records of book in braille available in three Brazilian public libraries, relating them to the normative documents that guide the Descriptive Representation. Although the focus of the research was the Descriptive Representation, wove a brief review on the Thematic Representation. Explicit search results, as well makes recommendations aimed at structuring OPACs and the development of more responsive bibliographic records for blind users.

Keywords: $\quad$ Cataloguing. Descriptive Representation. Visual Impairment. Book in Braille. 


\section{REFERÊNCIAS}

ARAUJO, Heloisa Costa Marrocos de. Acessibilidade para pessoas com deficiência visual na Biblioteca Central da UNIRIO. 2015. 93 f. Trabalho de Conclusão de Curso (Graduação em Biblioteconomia)-Universidade Federal do Estado do Rio de Janeiro, Rio de Janeiro, 2015. Disponível em: <http://www.unirio.br/unirio/ cchs/eb/arquivos/tccs-acima-de-9/TCC-\% 20 HELOISA \% 20COSTA \% 20MARROCOS $\% 20$ DE\%20ARAUJO.pdf>. Acesso em: 28 fev. 2016.

ASSOCIAÇÃO BAIANA DE CEGOS. Deficiência visual. Salvador, 2009. Disponível em: <http:// www.abcegos.org.br/deficiencia-visual/>. Acesso em: 10 mar. 2016.

ASSOCIAÇÃO BRASILEIRA DE NORMAS TÉCNICAS. NBR 15599: acessibilidade: comunicação na prestação de serviços. Rio de Janeiro, 2008. 38 p.

BARBOSA, Sidney; MEY, Eliane Serrão Alves; SILVEIRA, Naira Christofoletti. Vocabulário controlado para indexação de obras ficcionais. Brasília: Briquet de Lemos/Livros, 2005. vii, 54 p. (Prazer de fazer, 1).

BRASIL. Lei $\mathrm{n}^{\circ} 10.753$, de 30 de outubro de 2003. Institui a Política Nacional do Livro. Diário Oficial da União, Brasília, 31 out. 2003. Disponível em: <http://www.planalto.gov.br/ ccivil_03/leis/2003/L10.753.htm>. Acesso em: 1 mar. 2016.

CÓDIGO de catalogação anglo-americano. Preparado sob a direção do Joint Steering Committee for Revision of AACR. Tradução para a língua portuguesa sob a responsabilidade da Federação Brasileira das Associações de Bibliotecários, Cientistas da Informação e Instituições. 2. ed. rev. 2002. São Paulo: FEBAB, 2005. $2 \mathrm{v}$.

\section{FEDERAÇÃO}

DE ASSOCIAÇÕES E INSTITUIÇÕES BIBLIOTECÁRIAS. Bibliotecas para cegos na era da informação: diretrizes de desenvolvimento. Editado por Rosemary Kavanagh e Beatrice Christensen Sköld. Tradução de Maria Cléofas Faggion Alencar. São Paulo: Imprensa Oficial do Estado de São Paulo, 2009b. 99 f. (Relatório professional da IFLA, 86).

$\begin{array}{lr}\text { FEDERAÇÃO } & \text { INTERNACIONAL } \\ \text { DE ASSOCIAÇÕES E INSTITUIÇÕES }\end{array}$ BIBLIOTECÁRIAS. Declaração de princípios internacionais de catalogação. 2009a. 15 f. Disponível em: <http://www.ifla.org/files/ assets/cataloguing/icp/icp_2009-pt.pdf > . Acesso em: 11 out. 2015.

\section{FEDERAÇÃO}

DE ASSOCIAÇÕES E INSTITUIÇÕES BIBLIOTECÁRIAS. Grupo de Estudio sobre los Requisitos Funcionales de los Registros Bibliográficos. Requisitos funcionales de los registros bibliográficos: informe final. Traducción de Xavier Agenjo y Maria Luisa Martinez-Conde. [Espanha], 1998. 239 f. Disponível em: <http://www.ifla.org/files/ assets/cataloguing/frbr/frbr-es.pdf>. Acesso em: 22 out. 2015.

FUNDAÇÃO DORINA NOWILL PARA CEGOS. Livro braille. São Paulo, [2015a?]. Disponível em: <http:/ / www.fundacaodorina.org.br/o-quefazemos/livros-acessiveis/\#livros-em-braille>. Acesso em: 10 mar. 2016.

FUNDAÇÃO DORINA NOWILL PARA CEGOS. Livro digital Daisy. São Paulo, [2015b?]. Disponível em: <http://www.fundacaodorina. org.br/o-que-fazemos/livros-acessiveis/\#livrodigital-daisy>. Acesso em: 10 mar. 2016.

FUNDAÇÃO DORINA NOWILL PARA CEGOS. Livro falado. São Paulo, [2015c?]. Disponível em: <http://www.fundacaodorina.org.br/o-quefazemos/livros-acessiveis/\#biblioteca-do-livrofalado>. Acesso em: 10 mar. 2016.

FUNDAÇÃO DORINA NOWILL PARA CEGOS. O que é deficiência? São Paulo, [2015d?]. Disponível em: <http://www.fundacaodorina. org.br/deficiencia-visual/>. Acesso em: 10 mar. 2016.

FUNDAÇÃO GETÚlIO VARGAS. Censo Nacional das Bibliotecas Públicas Municipais: estudo quantitativo: principais resultados. 2010. 135 slides. Disponível em: <http://jornalggn. com.br/sites/default/files / documentos / Censo_Nacional_das_Bibliotecas_Publicas_ Municipais_1.pdf>. Acesso em: 3 mar. 2016. 
INSTITUTO BENJAMIN CONSTANT. O sistema braille no Brasil. Rio de Janeiro, 2005. Disponível em: <http://www.ibc.gov.br/?itemid=10235>. Acesso em: 10 mar. 2016.

INSTITUTO BRASILEIRO DE GEOGRAFIA E ESTATÍSTICA. Pesquisa nacional de saúde: 2013: ciclos de vida: Brasil e grandes regiões. Rio de Janeiro: IBGE, 2015. 92 p. Disponível em: <http:/ / biblioteca.ibge.gov.br/visualizacao/ livros/liv94522.pdf>. Acesso em: 10 mar. 2016.

MEY, Eliane Serrão Alves; SILVEIRA, Naira Christofoletti. Catalogação no plural. Brasília: Briquet de Lemos/Livros, 2009. 217 p.

ORGANIZAÇÃO MUNDIAL DA PROPRIEDADE INTELECTUAL. Tratado de Marraquexe. 2013. Disponível em: <http:// www.acessibilidade.gov.pt/pub/tratado_ marraquexe_pt.html>. Acesso em: 14 mar. 2016.

SASSAKI, Romeu Kazumi. Qual a grafia correta: Braille, braille ou braile? Depende. São
Paulo, 2005. Disponível em: <http://www. diversidadeemcena.net/braile04.htm>. Acesso em: 10 mar. 2016.

SISTEMA NACIONAL DE BIBLIOTECAS PÚBLICAS. Diretrizes. Acervo. [201-?]. Disponível em: <http://snbp.culturadigital.br/ diretrizesacervo/>. Acesso em: 2 mar. 2016.

TORRE, Diana Gutiérrez de La. O livro além do braille: aspectos relativos à edição e produção. 2014. 166 f. Dissertação (Mestrado em Ciências da Comunicação)-Universidade de São Paulo, São Paulo, 2014. Disponível em: <http://www. teses.usp.br/teses/disponiveis/27/27152/tde20012015-101252/pt-br.php>. Acesso em: 22 fev. 2016.

UNIÃO DOS CEGOS DO BRASIL. Nossa missão. Rio de Janeiro, [201-?]. Disponível em: <http:// uniaodoscegosnobrasil.org.br/missao. htm>. Acesso em: 11 mar. 2016. 